\title{
Coupling 3D Nano-pillar and Robust Film to Guide Li-ion Flux for Dendrite-free Lithium Metal Anodes
}

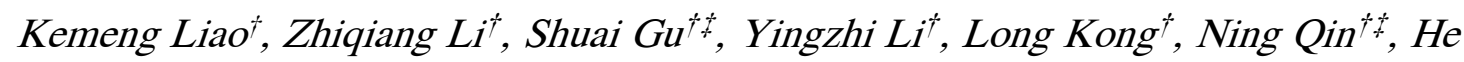
Huang ${ }^{\dagger}$, Sisi $\mathrm{Wu}^{\dagger}$, Jingjing Chen ${ }^{\dagger}$, Qingmeng Gan ${ }^{\dagger}$, Kaili Zhang ${ }^{\dagger}$ and Zhouguang Lu* ${ }^{*}$

$\dagger$ Department of Materials Science and Engineering, Shenzhen Key Laboratory of Interfacial Science and Engineering of Materials, Southern University of Science and Technology, Shenzhen 518055 Guangdong, P. R. China.

\$ Department of Mechanical Engineering, City University of Hong Kong, Kowloon, Hong Kong, P. R. China

*E-mail: luzg@sustech.edu.cn (Zhouguang Lu)

These authors contributed equally to this work.

KEYWORDS: Li metal anodes, Li-ion conduction, 3D nano-copper layer, Li-Nafion, Li dendrite, Li deposition 


\section{Supporting Figures}

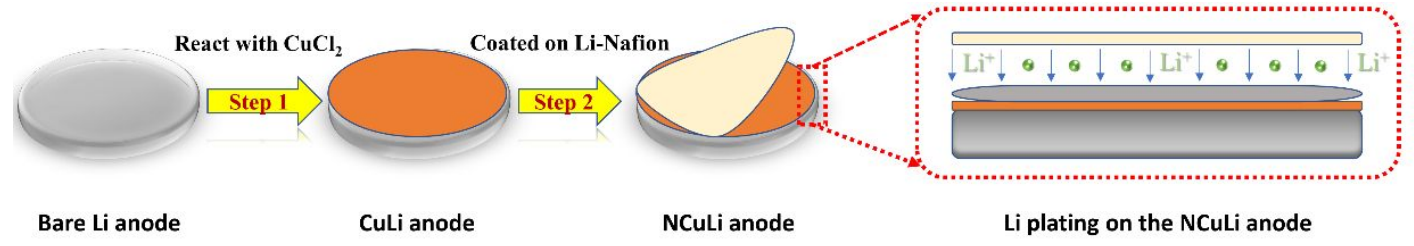

Figure S1. The fabrication process of $\mathrm{NCuLi}$ anodes 


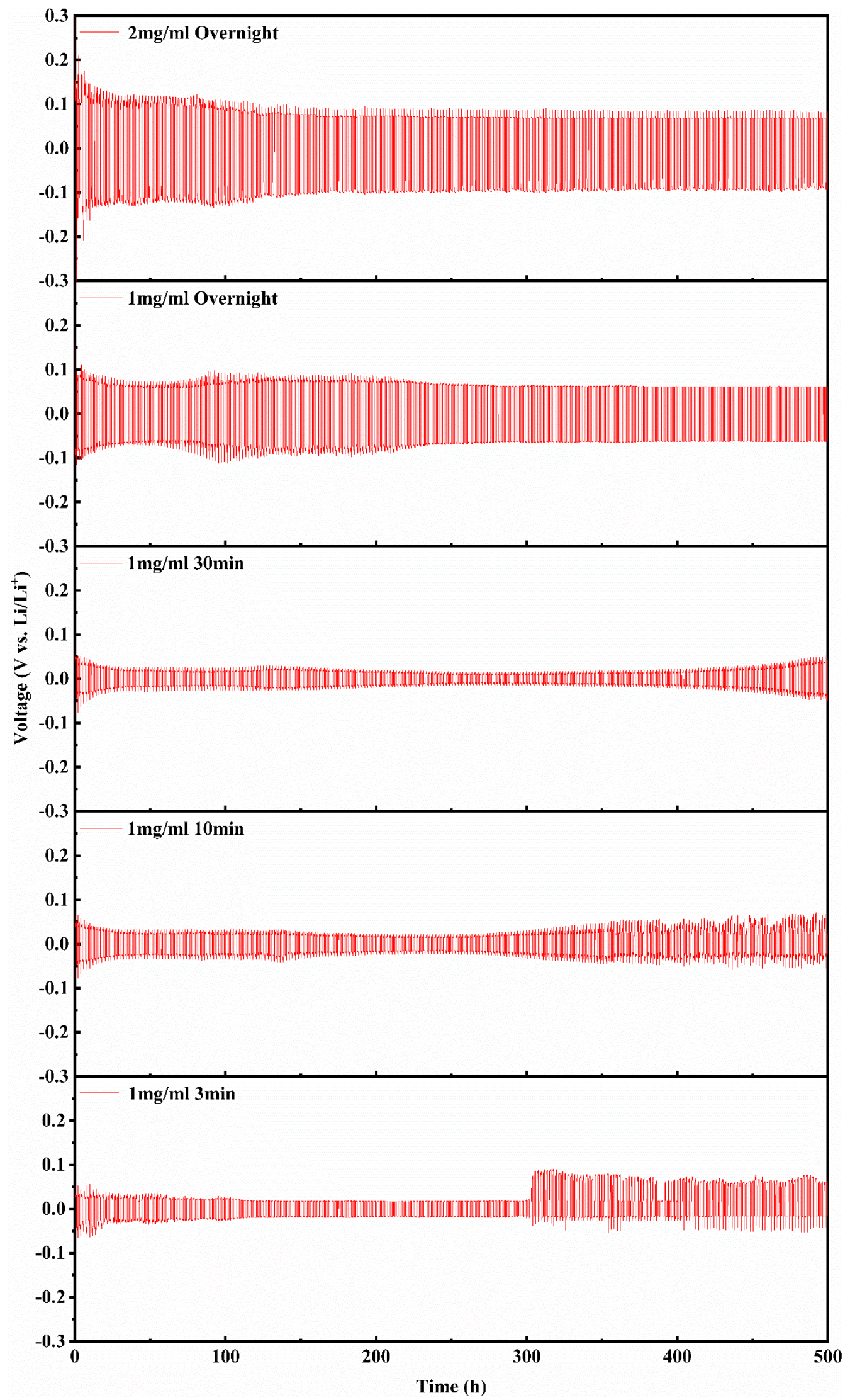

Figure S2. Voltage-time profiles of symmetric cells at a current density of $1 \mathrm{~mA} \mathrm{~cm}^{-2}$ and a capacity of $1 \mathrm{mAhcm}^{-2}$ for $\mathrm{CuLi}$ anodes after reacting different time with 
different concentration. 


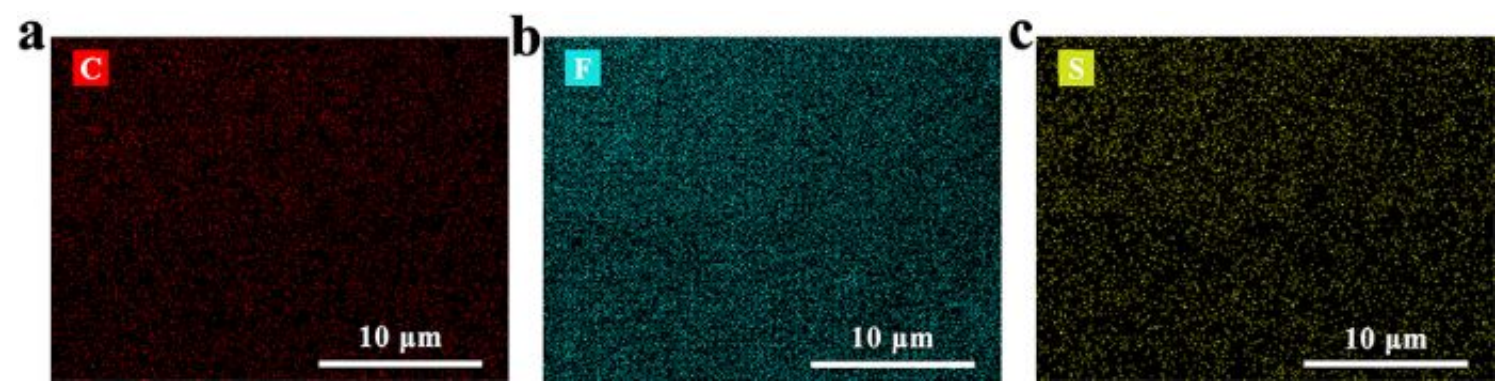

Figure S3. Corresponding EDS (a) C, (b) F and (c) S mapping of the NCuLi anode. 


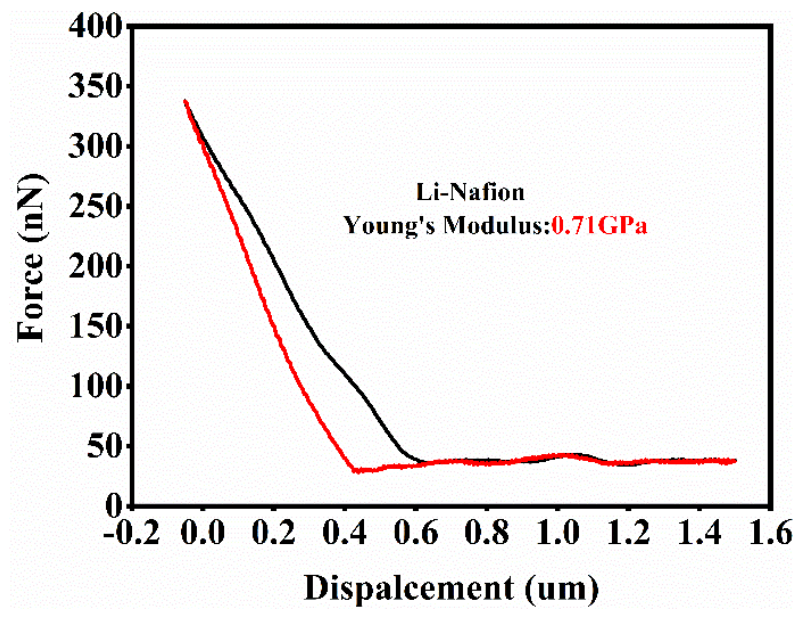

Figure S4. The force-distance curve and the corresponding Young's modulus value of the Li-Nafion film. 


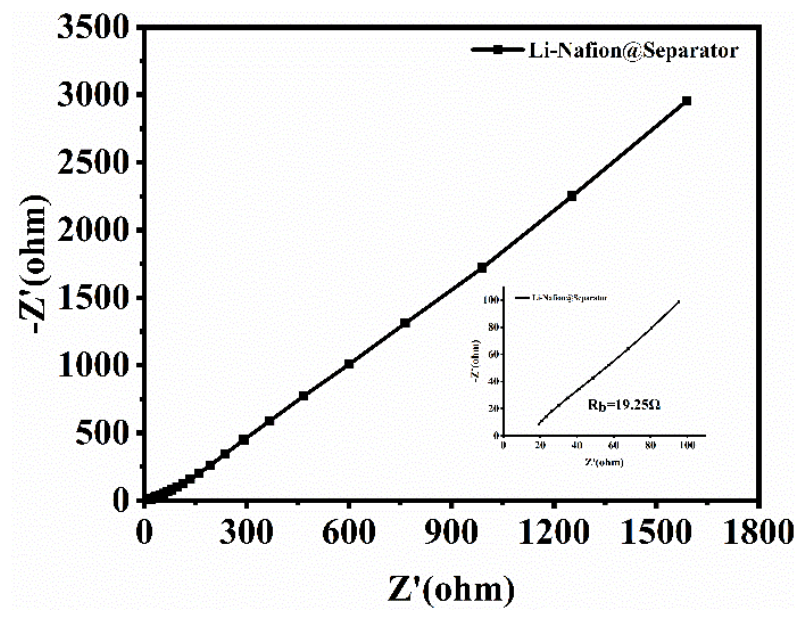

Figure S5. The impedance spectra to determine the ionic conductivity of the LiNafion film. 

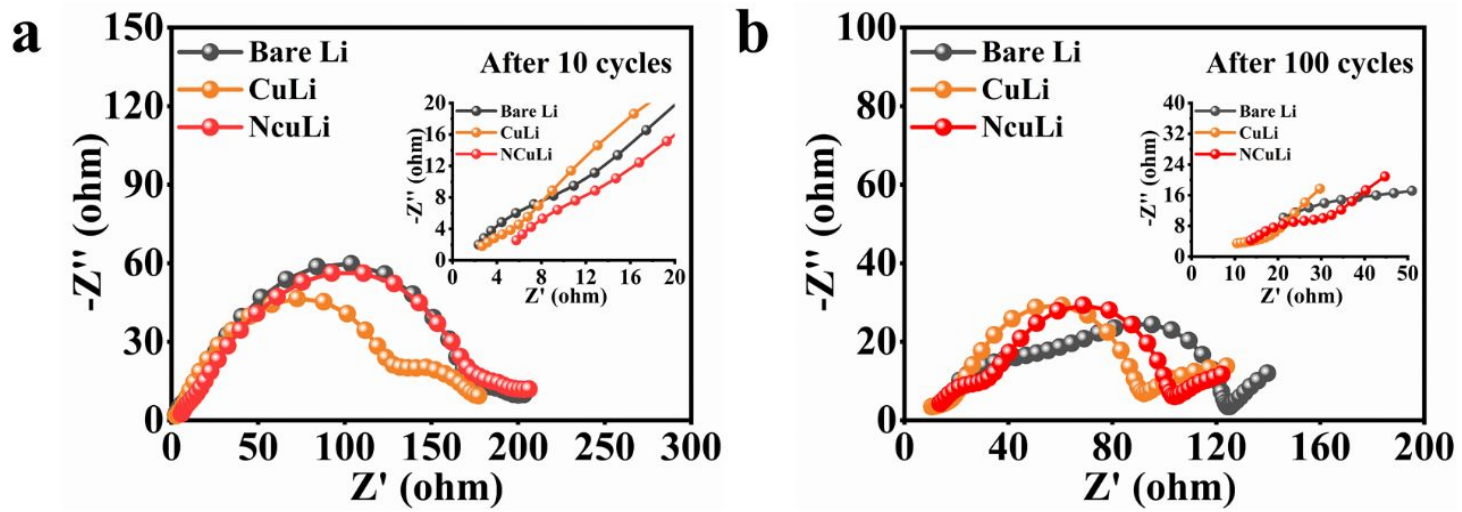

Figure S6. EIS spectrums of bare Li, CuLi and NCuLi symmetric cells after the (a) $10^{\text {th }}$ and (b) $100^{\text {th }}$ cycles at a current density of $1 \mathrm{~mA} \mathrm{~cm}{ }^{-2}$ with a total capacity of $1.0 \mathrm{mAh} \mathrm{cm}^{-}$ 2 . 

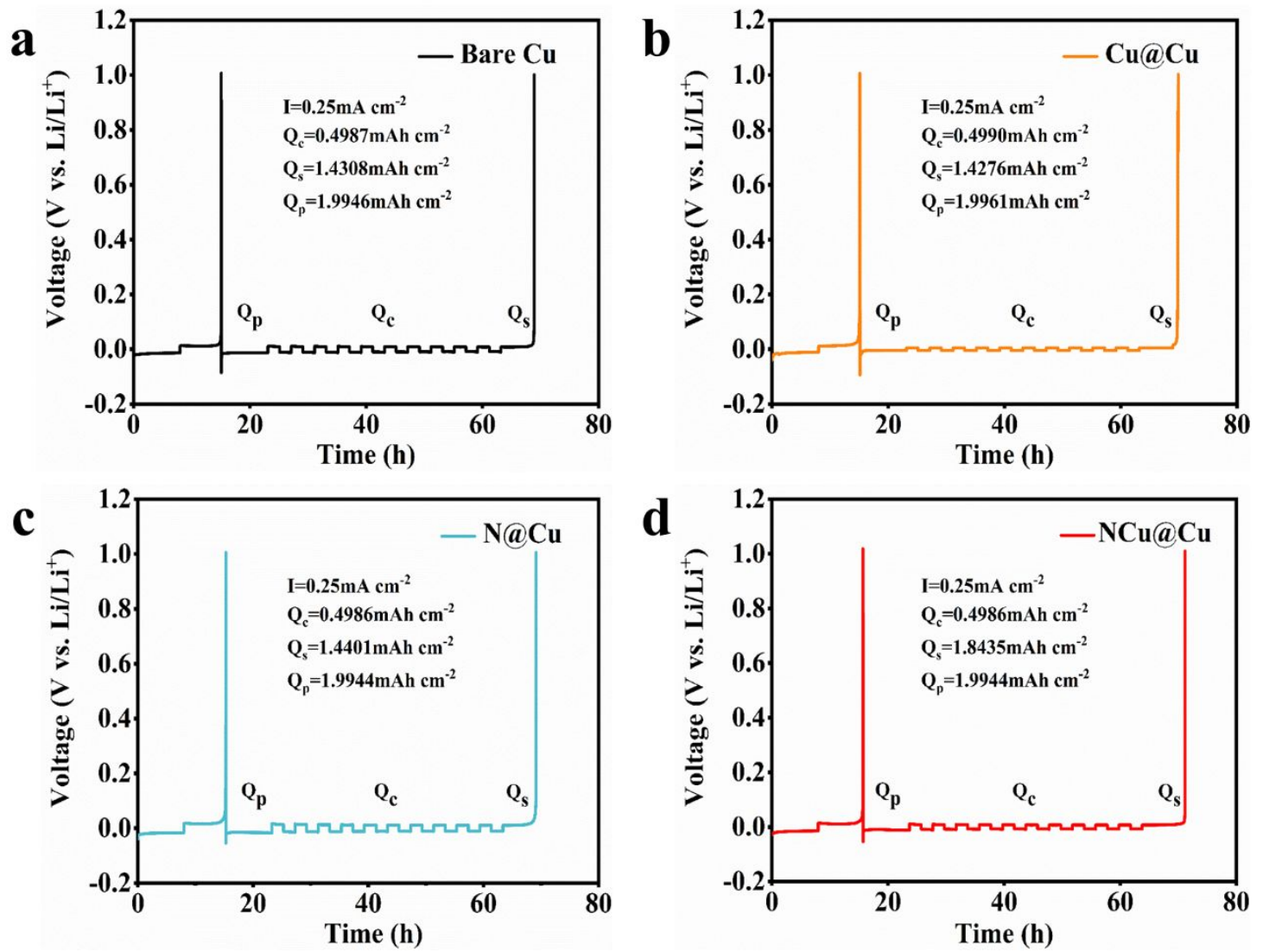

Figure S7. Voltage-time profiles of Li plating/stripping on (a) bare $\mathrm{Cu}$ foil, (b) 3D nano copper layer coated $\mathrm{Cu}$ foil $(\mathrm{Cu} @ \mathrm{Cu}$ electrode), (c) only Li-Nafion film coated $\mathrm{Cu}$ foil (N@Cu electrode) and (d) both 3D nano copper layer and Li-Nafion layer coated on $\mathrm{Cu}$ foil (NCu@Cu electrode) with the modified Aurbach method to test the average Li CEs. 


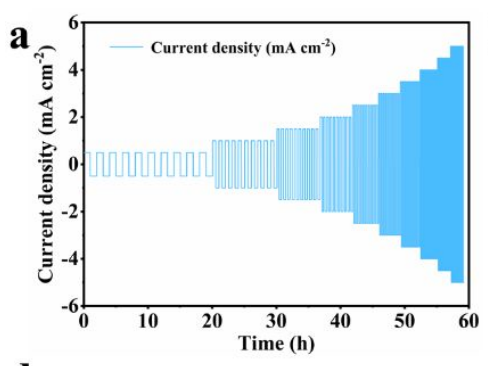

d

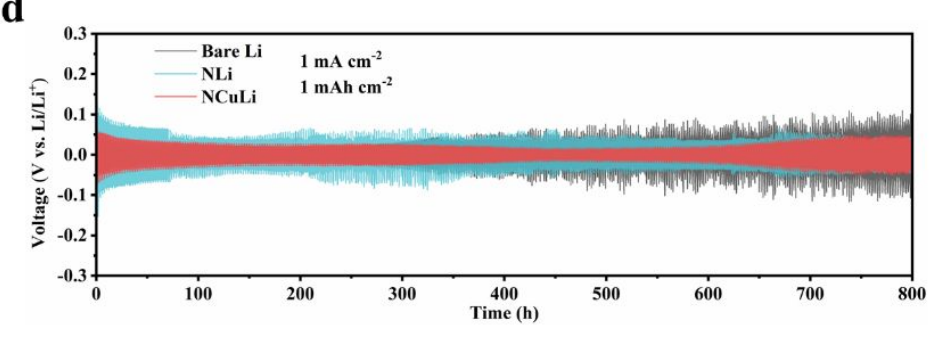

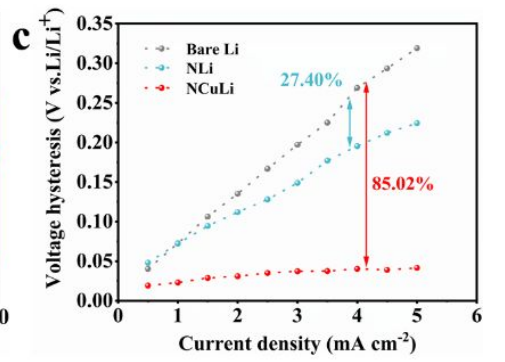

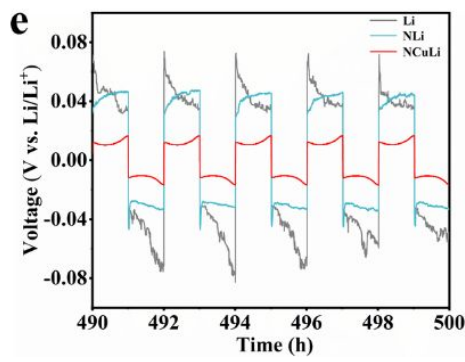

Figure S8. Further comparisons of cycling performance for NLi anodes. (a) The corresponding cycling current density from $0.5 \mathrm{~mA} \mathrm{~cm} \mathrm{~cm}^{-2}$ to $5 \mathrm{~mA} \mathrm{~cm} \mathrm{~cm}^{-2}$ for rate capability tests. (b) Voltage-time profiles of $\mathrm{Li}|| \mathrm{Li}, \mathrm{NLi}|| \mathrm{NLi}$ and $\mathrm{NCuLi} \| \mathrm{NCuLi}$ symmetric cells for rate capability tests. (c) Hysteresis plots of $\mathrm{Li}\|\mathrm{Li}, \mathrm{NLi}\| \mathrm{NLi}$, and $\mathrm{NCuLi} \| \mathrm{NCuLi}$ symmetric cells for rate capability tests. (d) The long cycle voltage-time performance of bare $\mathrm{Li}, \mathrm{NLi}$ and $\mathrm{NCuLi}$ symmetric cells at $1 \mathrm{~mA} \mathrm{~cm}^{-2}, 1 \mathrm{mAh} \mathrm{cm}^{-2}$. (e) Magnified voltagetime profiles at $490-500 \mathrm{~h}$ for various symmetric cells. 


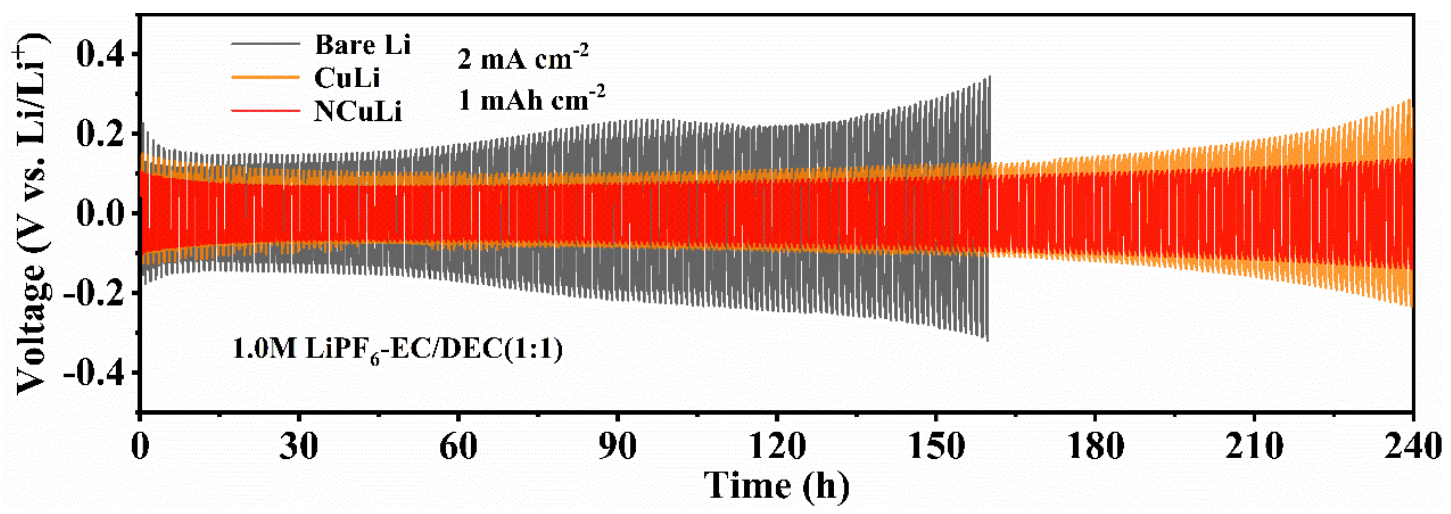

Figure S9. The voltage profiles of Li plating/stripping in bare $\mathrm{Li}, \mathrm{CuLi}$ and $\mathrm{NCuLi}$ symmetric cells in carbonate electrolyte at $2 \mathrm{~mA} \mathrm{~cm}{ }^{-2}$ for $1 \mathrm{mAh} \mathrm{cm}-2$. 


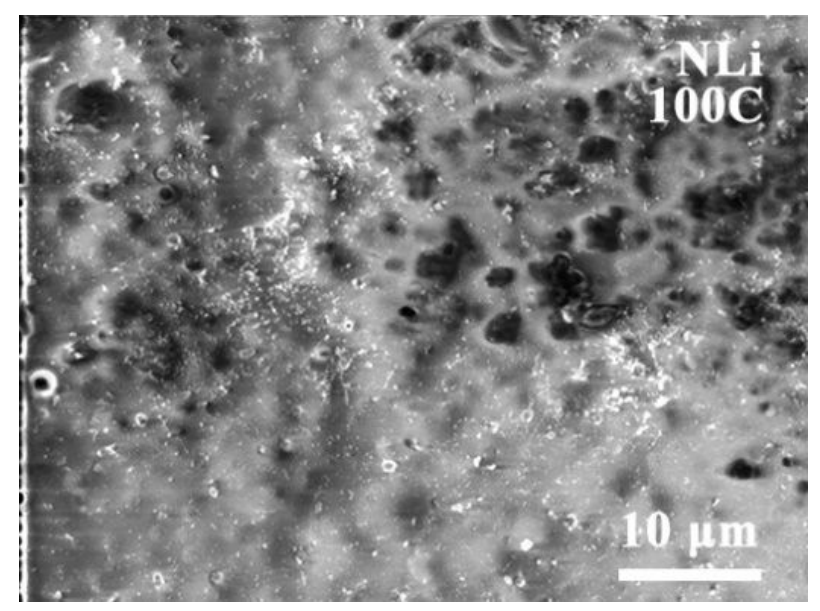

Figure S10. Corresponding SEM image of NLi anode surface after 100 cycles. 


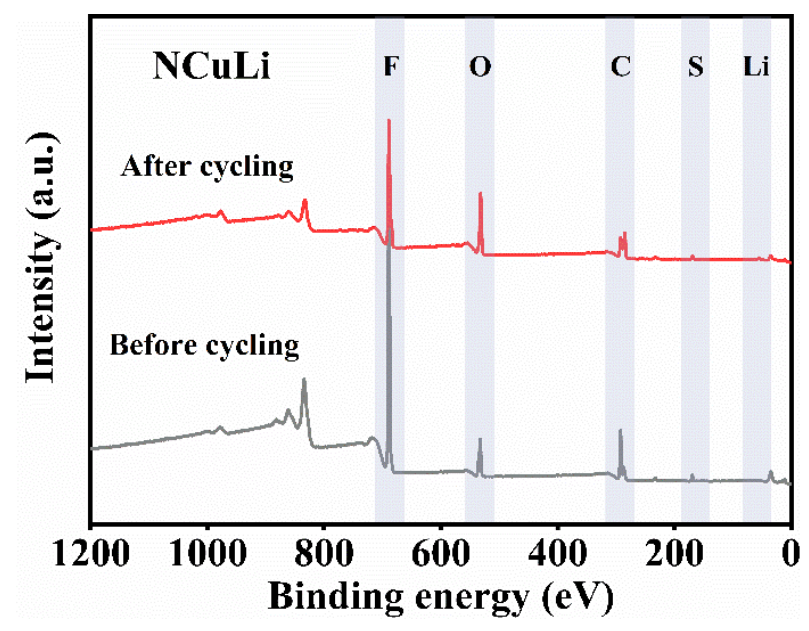

Figure S11. XPS spectrums of NCuLi anode before and after 50 cycles at $1 \mathrm{~mA} \mathrm{~cm}^{-2}$, $1 \mathrm{mAh} \mathrm{cm}^{-2}$. 


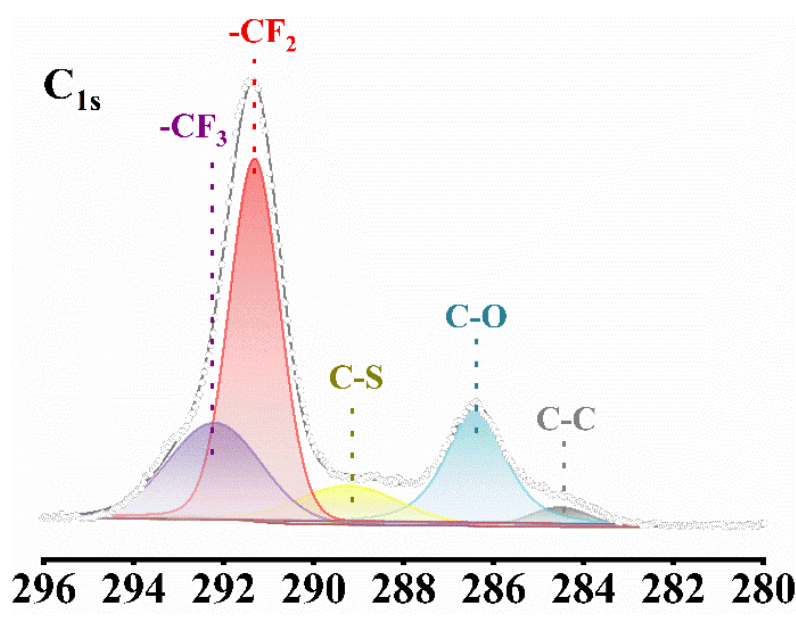

Figure S12. The $\mathrm{C}_{1 \mathrm{~s}}$ high-resolution XPS spectrum of $\mathrm{NCuLi}$ anode before cycling.

The $\mathrm{C}_{1 \mathrm{~S}}$ XPS spectrum of the NCuLi anode did not change significantly before and after cycling, indicating the integrity of the Nafion film structure and preventing the decomposition of the electrolyte on the electrode surface. 

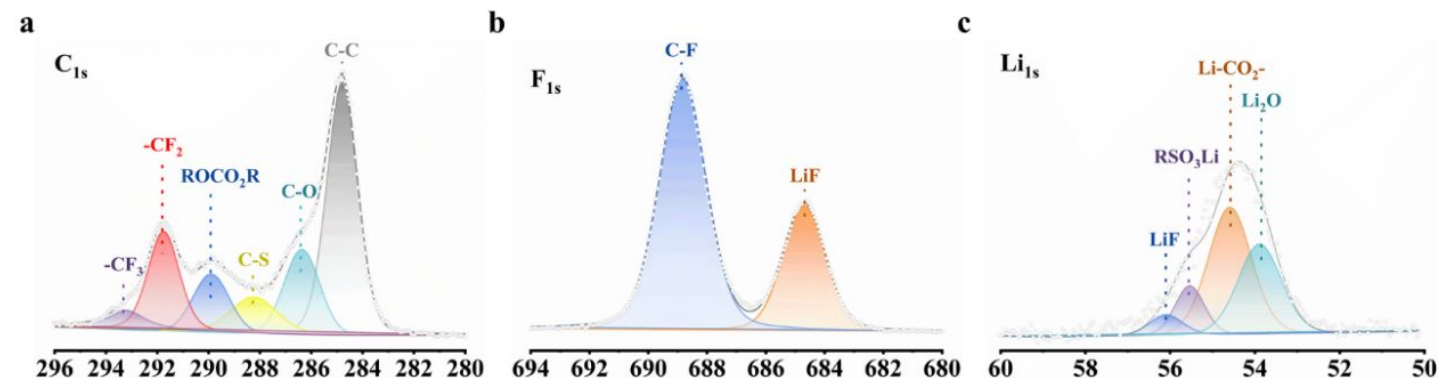

Figure S13. (a) $\mathrm{C}_{1 \mathrm{~s}}$, (b) $\mathrm{Li}_{1 \mathrm{~s}}$ and (c) $\mathrm{F}_{1 \mathrm{~s}}$ high-resolution XPS spectra of NLi anode surface after 50 cycles at a current density of $1 \mathrm{~mA} \mathrm{~cm}^{-2}$ and a capacity of $1 \mathrm{mAh} \mathrm{cm}^{-2}$. 


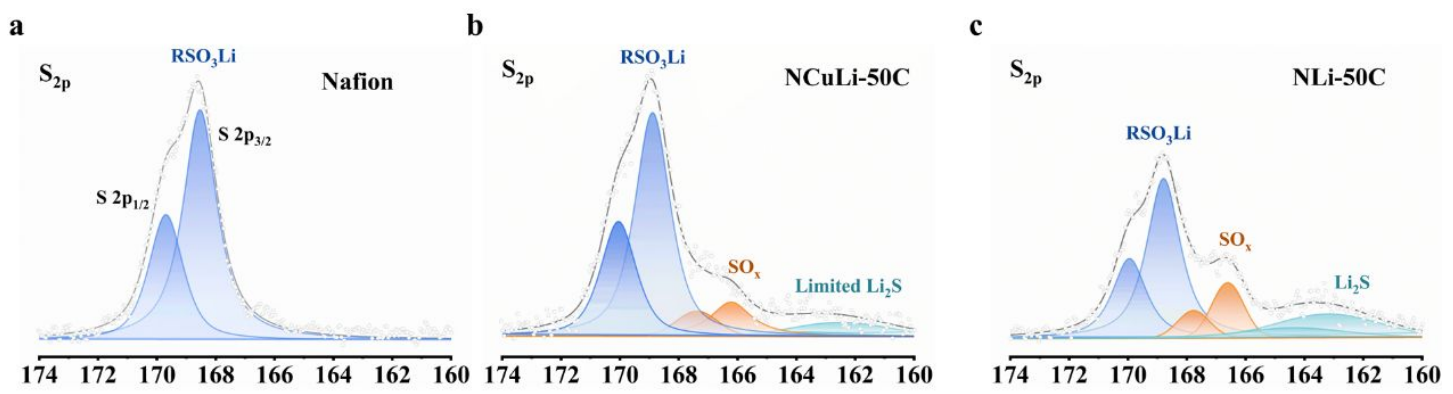

Figure S14. The $\mathrm{S}_{2 \mathrm{p}}$ high-resolution XPS spectra of (a) pure Nafion, (b) NCuLi anode and (c) NLi anode after 50 cycles. 


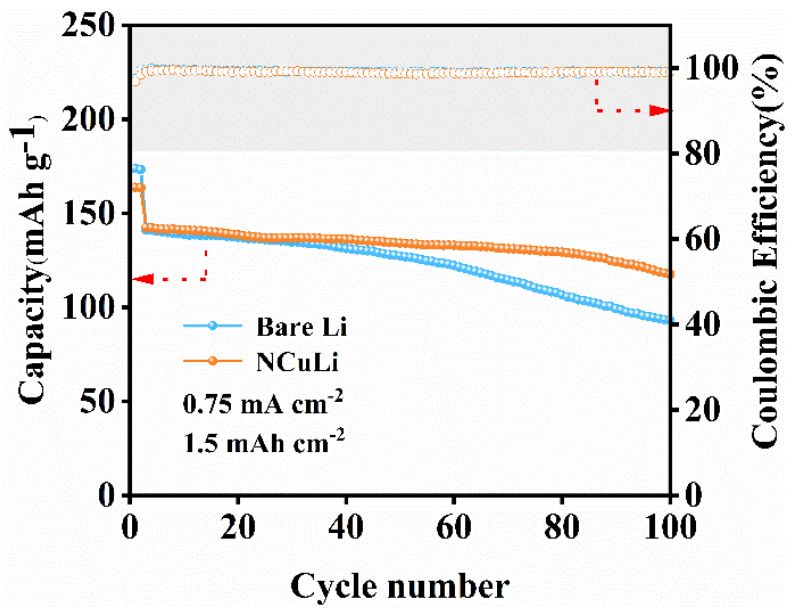

Figure S15. Cycling performances of the $\mathrm{Li} \| \mathrm{LiCoO}_{2}$ and $\mathrm{NCuLi} \| \mathrm{LiCoO}_{2}$ full cells with high areal capacity at $0.75 \mathrm{~mA} \mathrm{~cm}^{-2}$ for $1.5 \mathrm{~mA} \mathrm{~h} \mathrm{~cm}^{-2}$. 